\title{
Successful Endoscopic Management of Suspected Foreign Bodies in Upper Gastrointestinal Tract among Patients Undergoing Upper Gastrointestinal Endoscopy in a Tertiary Care Hospital: A Descriptive Cross-sectional Study
}

\author{
Ramila Shrestha, ${ }^{1}$ Shankar Baral, ${ }^{1}$ Mukesh Sharma, ${ }^{1}$ Jiwan Thapa, ${ }^{1}$ Dibas Khadka' \\ 'Department of Gastroenterology, National Academy of Medical Sciences, Bir Hospital, Kathmandu, Nepal.
}

\section{ABSTRACT}

Introduction: Most ingested foreign bodies pass through the gastrointestinal tract spontaneously. However, some foreign bodies may get impacted in the upper gastrointestinal tract. A variety of endoscopic techniques and instruments are indicated for the removal of such impacted foreign bodies. This study was conducted to find out the prevalence of successful endoscopic removal of foreign bodies.

Methods: This descriptive cross-sectional study was conducted among patients who presented at the Department of Gastroenterology with complaints of upper gastrointestinal foreign body ingestion from 2/11/2008 to 23/07/2020 after taking ethical approval of the research proposal was taken from Institutional Review Board (Reference no 13). Convenient sampling was done. The data were entered into Microsoft Excel and analyzed in Statistical Package of Social Sciences version 22.

Results: A total of 119 cases were identified with foreign bodies ingestion. In hundred patients, foreign bodies 100 (84 \%) (77.41-90.58 at 95\% Confidence Interval) were extracted completely. Complete extraction failed in $19(16 \%)$ patients. Six (5\%) patients were treated by push technique and $10(8.4 \%)$ patients with failed retrieval, received surgical intervention for foreign body removal.

Conclusions: Endoscopic removal technique of foreign bodies in the upper gastrointestinal tract was successful in most of the cases and is associated with few complications.

Keywords: endoscopes; foreign bodies; gastrointestinal tract.

\section{INTRODUCTION}

The impaction of an ingested substance is a frequent cause of gastrointestinal emergencies. ${ }^{1}$ About 1020 percent of such ingested foreign bodies require an endoscopic removal and less than one percent of patients will require surgical removal. ${ }^{2}$ In adults, impaction of bone or meat bolus occurs during eating. ${ }^{3}$ Impaction of non-food objects occurs in patients with psychiatric disorders, developmental delay, and alcohol intoxication. ${ }^{4}$ Foreign bodies often lodge in the esophagus because of the object size, shape, narrowing of the esophagus lumen, or anatomic abnormalities..$^{5-7}$

Patients with esophageal foreign bodies are almost always symptomatic. ${ }^{8-9}$ Potential complications of esophageal foreign bodies include laceration, punctures with associated abscess, perforations, mediastinitis, pneumomediastinum, pneumothorax, and injuries to the aorta or pulmonary vasculature. ${ }^{10}$ Various endoscopic techniques and instruments are used for the removal of these foreign bodies. ${ }^{7,11}$

Our study aimed to find out the prevalence of successful endoscopic removal of foreign bodies.

Correspondence: Dr. Ramila Shrestha, Department of Gastroenterology, National Academy of Medical Sciences, Bir Hospital, Kathmandu, Nepal. Email: ramilamaskey250@ gmail.com, Phone: +977-9851082922. 


\section{METHODS}

A descriptive cross-sectional study was conducted after obtaining ethical approval from the Institutional Review Committee (Reference number No.13) of the National Academy of Medical Sciences. Data was collected from $20 / 01 / 2008$ to $23 / 07 / 2020$ retrospectively. The study was conducted at Gastroenterology Unit, Medicine Department, National Academy of Medical Sciences, Bir Hospital. The study included all patients with a history of impacted foreign bodies, confirmed by endoscopy in more than 18 years of age group. We excluded patients with a history of ingested foreign bodies but not detected on endoscopy, patients referred to other centers, incomplete records, or who underwent direct surgical intervention. All medical records including age, sex, type of foreign body, associated signs and symptoms, used endoscopic devices were reviewed. The sample size was calculated as follows,

$$
\begin{aligned}
\mathrm{n} & =\mathrm{Z}^{2} \times \mathrm{p} \times \mathrm{q} / \mathrm{e}^{2} \\
& =\left(1.96^{2}\right) \times(0.956) \times(1-0.956) /(0.04)^{2} \\
& \approx 101
\end{aligned}
$$

Where,

$\mathrm{n}=$ required sample size

$Z=1.96$ at $95 \%$ Confidence Interval (Cl)

$\mathrm{p}=$ prevalence of success rate in foreign body extraction as per Emra, et al. $95.6 \%{ }^{16}$

$q=1-p$

$\mathrm{e}=$ margin of error, $4 \%$

Taking the non-response rate $10 \%$, the calculated sample size is 111 .

However, 119 participants were included in our study. Convenient sampling was done. Written consent was obtained from all the participants.

Various instruments (Forceps and Dormia baskets) were used to retrieve the impacted foreign bodies. Repeat endoscopy was done after the foreign body retrieval.

The data were entered into Microsoft Excel and analyzed in Statistical Package of Social Sciences version 22.

\section{RESULTS}

The total number of participants in our study was 119 . In 100 (84\%) (77.41-90.58 at 95\% Confidence Interval) patients, foreign bodies were extracted completely. Complete extraction failed in $19(16 \%)$ patients. Among patients in whom the foreign body was extracted completely, $58(79.5 \%)$ were male patients and 42 $(91.3 \%)$ were female patients. Six $(5 \%)$ patients were treated by push technique and $10(8.4 \%)$ patients with failed retrieval, received surgical intervention for foreign body removal.

The percentage of complete removal was only 5 (56\%) for $<25$ years of age but nearly 34 (87\%) for $25-49$ years and $40(87 \%)$ in $50-74$ years. Complete removal was $21(83.3 \%)$ for the 75 years and above age group. About 42 (92\%) of females and $58(79.5 \%)$ of male patients had complete removal of foreign body. About $89(87 \%)$ of cases with food as the foreign body had complete removal whereas $11(68.8 \%)$ of non-food items were completely removed. Around 89 (83\%) of the items located in the esophagus were removed completely whereas $11(100 \%)$ of the non-esophagus items were removed. The complete removal percentage

\begin{tabular}{|c|c|c|c|}
\hline \multicolumn{4}{|c|}{$\begin{array}{l}\text { Table 1. Complete and failed removal in different } \\
\text { groups. }\end{array}$} \\
\hline Age & $\begin{array}{l}\text { Complete } \\
\text { removal } n \\
(\%)\end{array}$ & $\begin{array}{l}\text { Failure to } \\
\text { remove } \\
\text { completely } n \\
(\%)\end{array}$ & $\begin{array}{l}\text { Total n } \\
(\%)\end{array}$ \\
\hline$<25$ & $5(55.6)$ & $4(44.4)$ & $9(7.5)$ \\
\hline $25-49$ & $34(87.2)$ & $5(12.8)$ & $\begin{array}{l}39 \\
(32.77)\end{array}$ \\
\hline $50-74$ & $40(87)$ & $6(13)$ & $\begin{array}{l}46 \\
(38.65)\end{array}$ \\
\hline $75+$ & $21(84)$ & $4(16)$ & $\begin{array}{l}25 \\
(21.00)\end{array}$ \\
\hline \multicolumn{4}{|l|}{ Sex } \\
\hline Female & $42(91.3)$ & $4(8.7)$ & $\begin{array}{l}46 \\
(38.65)\end{array}$ \\
\hline Male & $58(79.5)$ & $15(20.5)$ & $\begin{array}{l}73 \\
(61.34)\end{array}$ \\
\hline \multicolumn{4}{|c|}{ Type of Foreign body } \\
\hline Food & $89(86.4)$ & $14(13.6)$ & $\begin{array}{l}103 \\
(86.55)\end{array}$ \\
\hline Non-food & $11(68.8)$ & $5(31.2)$ & $\begin{array}{l}16 \\
(13.44)\end{array}$ \\
\hline \multicolumn{4}{|c|}{ Foreign body location } \\
\hline Esophagus & $89(82.4)$ & $19(17.6)$ & $\begin{array}{l}108 \\
(90.75)\end{array}$ \\
\hline Non Esophagus & $11(100)$ & 0 & $11(9.2)$ \\
\hline \multicolumn{4}{|l|}{ Accessories } \\
\hline Forceps & $42(84)$ & $8(16)$ & $\begin{array}{l}50 \\
(42.01)\end{array}$ \\
\hline Dormia Basket & $58(84.1)$ & $11(15.9)$ & $\begin{array}{l}69 \\
(57.98)\end{array}$ \\
\hline
\end{tabular}
using forceps and Dormia basket was nearly the same (Table 1).

Seventy-three $(61.3 \%)$ patients were male and 46 $(38.3 \%)$ were female. One hundred and three $(86.6 \%)$ cases of ingested foreign bodies were food whereas nonfood were in $16(13.4 \%)$ patients respectively. Chicken bone and chicken were found in 51 (42.9\%) patients and 29 (24.4\%) patients respectively. Some patients had ingested fruit seeds, lapsi in 7 (5.9\%) patients, and mango seed in $1(0.8 \%)$. Other ingested meat like buff and mutton were observed in $6(5 \%)$ patients and $4(3.4 \%)$ patients respectively. Fishbone was found 
Shrestha et al. Successful Endoscopic Management of Suspected Foreign Bodies in Upper Gastrointestinal Tract among Patients Undergoing...

in $3(2.5 \%)$. Jack fruit, a lump of food, vegetables were visualized in $1(0.8 \%)$. True foreign bodies (nonfood) were found in $16(13.4 \%)$. Five $(4.2 \%)$ had accidentally ingested dentures. The wire was seen in 4 (3.3\%) patients with denture impaction. Coin, hair, part of Percutaneous Endoscopic Gastrostomy (PEG) tube, pin, stone, and two buttons were observed in only 1 (0.8\%) (Table 2).

\begin{tabular}{|ll|}
\hline $\begin{array}{l}\text { Table 2. Profile of patients with upper gastrointestinal } \\
\text { tract foreign bodies }(\mathbf{n}=119) .\end{array}$ \\
\hline Age (years) & $\mathbf{n}(\%)$ \\
$<25$ & $9(7.6)$ \\
$25-49$ & $39(32.8)$ \\
$50-74$ & $46(38.7)$ \\
$75+$ & $25(21.0)$ \\
Sex & \\
Female & $46(38.7)$ \\
Male & $73(61.3)$ \\
Type of foreign body & $103(86.6)$ \\
Food & $16(13.4)$ \\
Non-food & \\
Foreign body location & $108(90.8)$ \\
Esophagus & $11(9.2)$ \\
Non-esophagus & \\
Accessories & $50(42.0)$ \\
Forceps & $69(58.0)$ \\
Dormia basket & $100(84.0)$ \\
Outcome & $19(16.0)$ \\
Complete removal & \\
Failure to remove completely & \\
\hline
\end{tabular}

About 46 (39\%) of cases were of age 50-74 followed by $25-49$ of $39(32.8 \%), 75$ and above the age 25 $(21 \%)$. About $9(8 \%)$ of cases were less than 25 years of age. Nearly $10387 \%$ of the cases were related to food items. In about 108 (91\%) of the location was esophagus. The most widely used tool was the Dormia basket followed by Shark tooth forceps, Crocodile forceps, and rat tooth forceps. 69 (58\%) of cases were treated with a Dormia basket and the remaining using forceps.

\section{DISCUSSION}

In this study, a total number of 119 patients had foreign body impaction in the upper gastrointestinal tract. Endoscopic procedures were performed in almost all patients within 24 hours of attending the hospital. Foreign body impaction was more prevalent in male patients $(61.3 \%)$. These findings were consistent with several studies from eastern and western regions. ${ }^{12-17 .}$ Our study concluded that the most common foreign bodies were food boluses, located in the esophagus $(90.8 \%)$. Various other studies have suggested the esophagus as the common site of impaction of foreign bodies. ${ }^{12,13,16,18-20}$ Mosca $S$, et al. showed almost all the foreign bodies were found in the esophagus. ${ }^{21}$
In a prospective study done by Shrestha $D$, et al. from Nepal in patients with a clinical diagnosis of esophageal foreign body from July 2013 to July 2017, out of 101 cases of esophageal foreign body, there were $57 \%$ cases of chicken bone, followed by $17 \%$ mutton bone and $12 \%$ meat bolus which was consistent with our study. ${ }^{23}$ A study from Manipal Teaching Hospital by Koirala K, et al. compared esophageal foreign bodies in pediatric and adult populations the result of which showed that out of total cases of foreign body impaction, $44.4 \%$ of patients were children and $55.5 \%$ were adults. The coin was the most common foreign body in the pediatric population $(82.1 \%)$ whereas bones were the commonest ones (91.4\%) in adults. ${ }^{24}$ Two previous studies from Nepal showed chicken bones were a common foreign body. ${ }^{25-6}$ Bony foreign bodies comprised the majority of identified foreign bodies. ${ }^{19}$ In our study, the majority of foreign bodies were pieces of bone (chicken bone $42.9 \%$ and fishbone $2.5 \%$ ) and meat boluses. The other foreign bodies included food boluses, fruit seeds, dentures, wire, coin, button, hair, stones were found in each patient $(0.8 \%)$. In our study, most patients were in the age group of $50-74$ years $(38.7 \%)$, followed by $25-49$ years $(32.8 \%)$. The most common age group was the fifth decade of life in a previous study from Nepal and India. ${ }^{23}$

Different endoscopic methods and equipments were used depending upon the types of foreign bodies. Food bolus was removed either in bloc or in a piecemeal fashion with help of a retrieval basket or forceps. Endoscopic management was done in 109 patients. Among them, complete extraction of foreign bodies was achieved with the help of Dormia basket in 58 patients $(84.1 \%)$, followed by various types of forceps or snare. Gentle pressure was applied with the tip of the endoscope to the esophageal food bolus, following air insufflation The most frequently used accessory devices were retrieval baskets ( $n=69,58 \%$ ), retrieval forceps, or polypectomy snares ( $n=50,42 \%$ ). Other studies also showed retrieval net, rat tooth forceps as common retrieval systems used. It is suggested from animal studies and clinical practice that the retrieval net is appropriate for the removal of smooth objects (coins, disc batteries, or magnets). ${ }^{27-8}$

In our study, one denture without wire could be removed from the esophagus but failed to retrieve in 4 patients $(80 \%)$. Open thoracotomy was required in one patient to remove such a foreign body. Those foreign bodies are likely to cause laceration and perforation because of impaction in the esophagus. Ill-fitting dentures may easily dislodge in the esophagus during chewing food or drinking. Three $(75 \%)$ cases were referred to the otolaryngology department. A similar study from the ENT department of the same center showed meat and bone $(68.33 \%)$ were the commonest foreign body 
in the esophagus, followed by dentures (15.5\%). All dentures were removed under conscious sedation but one required open thoracotomy. ${ }^{25}$ We reported a $98.8 \%$ success rate of endoscopic removal of foreign bodies and a $1.25 \%$ failure rate whereas a study from China success rate was $94.1 \%$ and the failure rate was $5.9 \%$. Most of the foreign bodies that fail endoscopic removal were dental prostheses, iron slices, or complex and ultra-long objects. ${ }^{5}$

In a study done by $\mathrm{Yao} \mathrm{CC}$, et al. endoscopic management was a safe and highly effective procedure in extracting foreign body ingestion and food bolus impaction. $93.5 \%$ of foreign bodies in the current study cohort were successfully extracted and 5 patients required surgical interventions. ${ }^{29}$ Similarly Wu WT, et al. also focused on the early intervention within 24 hours for minimizing the complications. A total of 172 patients $(52.7 \%)$ were found to have ingested foreign bodies; $73.5 \%$ were removed smoothly, $10.3 \%$ were treated by push technique and $16.0 \%$ with failed retrieval received alternative treatments. ${ }^{30}$

The most common underlying pathology was esophageal stricture (38 cases, $53.5 \%$ ). Nearly half of the patients $(49.9 \%)$ developed complications. As the duration of impaction increased, the success rate by endoscopy decreased. ${ }^{19}$

\section{CONCLUSIONS}

Most upper $\mathrm{Gl}$ foreign bodies in adults are related to food bolus impaction with bone and meat. Therapeutic endoscopy by an experienced skilled endoscopist with suitable accessories is a reliable, safe, and effective method in managing foreign bodies from the upper gastrointestinal tract.

Conflict of Interest: None.

\section{REFERENCES}

1. Schwartz GF, Polsky HS. Ingested foreign bodies of the gastrointestinal tract. Am Surg. 1976 Apr;42(4):236-8. [PubMed]

2. ParkJH, Park CH, ParkJH, LeeSJ, Lee WS, Joo YE, et al. Review of 209 cases of foreign bodies in the upper gastrointestinal tract and clinical factors for successful endoscopic removal. Korean J Gastroenterol. 2004 Apr;43(4):226-33. [라bMed | Full Text]

3. Sugawa C, Ono H, Taleb M, Lucas CE. Endoscopic management of foreign bodies in the upper gastrointestinal tract: A review. World J Gastrointest Endosc. 2014 Oct 16;6(10):475-81. [PubMed | Full Text | DOI]

4. Blaho KE, Merigian KS, Winbery SL, Park LJ, Cockrell M. Foreign body ingestions in the emergency department: case reports and review of treatment. J Emerg Med. 1998 Jan-Feb;16(1):21-6. [PubMed | Full Text | DOI]

5. Webb WA. Management of foreign bodies of the upper gastrointestinal tract: update. Gastrointest Endosc. 1995 Jan;41(1):39-51. [ PubMed | Full Text | DOI]

6. Smith MT, Wong RK. Foreign bodies. Gastrointest Endosc Clin N Am. 2007;17(2):361-82. [uued | Full Text | DOI]

7. Birk M, Bauerfeind P, Deprez PH, Hafner M, Hartmann D, Hassan C, et al. Removal of foreign bodies in the upper gastrointestinal tract in adults: European Society of Gastrointestinal Endoscopy (ESGE) Clinical Guideline. Endoscopy. 2016 May;48(5):489-96. [라Med | Full Text | DOI]

8. Ambe P, Weber SA, Schauer M, Knoefel WT. Swallowed foreign bodies in adults. Dtsch Arztebl Int. 2012 Dec;109(50):869-75. [PubMed | Full Text | DOI]

9. ASGEStandards of Practice Committee, Ikenberry SO, Jue TL, Anderson MA, Appalaneni V, Banerjee S, et al. Management of ingested foreign bodies and food impactions. Gastrointest Endosc. 2011 Jun;73(6):1085-91. [PubMed | Full Text | DOI]
10. Stack LB, Munter DW. Foreign bodies in the gastrointestinal tract. Emerg Med Clin North Am. 1996 Aug;14(3):493-521. [PubMed | Full Text | DOI]

11. Berggreen PJ, Harrison E, Sanowski RA, Ingebo K, Noland $\mathrm{B}$, Zierer S. Techniques and complications of esophageal foreign body extraction in children and adults. Gastrointest Endosc. 1993 Sep-Oct;39(5):626-30. [PubMed | Full Text | $\underline{\mathrm{DOI}}$

12. Yuan F, Tang X, Gong W, Su L, Zhang Y. Endoscopic management of foreign bodies in the upper gastrointestinal tract: An analysis of 846 cases in China. Exp Ther Med. 2018 Feb;15(2):1257-62. [ubMed | Full Text $\mid$ DOI]

13. Zhang S, Cui Y, Gong X, Gu F, Chen M, Zhong B. Endoscopic management of foreign bodies in the upper gastrointestinal tract in South China: a retrospective study of 561 cases. Dig Dis Sci. 2010 May;55(5):1305-12. [PubMed | Full Text | DOI]

14. Conway WC, Sugawa C, Ono H, Lucas CE. Upper GI foreign body: an adult urban emergency hospital experience. Surg Endosc. 2007 Mar;21(3):455-60. [PubMed | Full Text | DOI]

15. Velitchkov NG, Grigorov GI, Losanoff JE, Kjossev KT. Ingested foreign bodies of the gastrointestinal tract: retrospective analysis of 542 cases. World J Surg. 1996 Oct;20(8):1001-5. [uㅏㄹed | Full Text | DOI]

16. Emara MH, Darwiesh EM, Refaey MM, Galal SM. Endoscopic removal of foreign bodies from the upper gastrointestinal tract: 5-year experience. Clin Exp Gastroenterol. 2014 Jul 16;7:249-53. [uuMed | Full Text | DOI]

17. Chaudhari SKS, Chaudhary SM. Endoscopic management of foreign bodies in the upper gastrointestinal tract. Int Sur J. 2020 Jul;7(7):2226-30. [Full Text | DOI]

18. Ahmed Z, Mutillah S, Zahid T, Marfani MS. Upper Gastrointestinal foreign bodies: Presentation and management. Pakistan Journal of Surgery. 2009;25(2):106-9. [Full Text] 
19. Geng C, Li X, Luo R, Cai L, Lei X, Wang C. Endoscopic management of foreign bodies in the upper gastrointestinal tract: a retrospective study of 1294 cases. Scand J Gastroenterol. 2017 Nov;52(11):1286-91. [PubMed | Full Text | $\underline{\mathrm{DOI}}]$

20. Li ZS, Sun ZX, Zou DW, Xu GM, Wu RP, Liao Z. Endoscopic management of foreign bodies in the upper-GI tract: experience with 1088 cases in China. Gastrointest Endosc. 2006 Oct;64(4):485-92. [PubMed | Full Text | DOI]

21. Mosca S, Manes G, Martino R, Amitrano L, Bottino V, Bove A, et al. Endoscopic management of foreign bodies in the upper gastrointestinal tract: report on a series of 414 adult patients. Endoscopy. 2001 Aug;33(8):692-6. [․ㅏbMed | Full $\underline{\text { Text }} \mid \underline{\mathrm{DOI}}]$

23. Shrestha D. Management of esophageal foreign body using endoscopic approach: An experience from Kathmandu Medical College Teaching Hospital. Journal of Kathmandu Medical College. 2017 Oct-Dec;6(22):136-9. [Full Text | DOI]

24. Koirala K, Rai S, Chhetri S, Shah R. Foreign body in the esophagus-comparison between adult and pediatric population. Nepal Journal of Medical Sciences. 2012;1(1):42-4. [Full Text $\mid \underline{\text { DOI] }}$

25. Sharma B, Dhakal MP, Shakya G, Shrestha L. Foreign body in the oesophagus. 2004 Nov;5(1):. [ $\underline{\text { PubMed }} \mid \underline{\text { Full Text }}$ | DOI]

26. Chaudhary S, Khatri P, Shrestha S. Effectiveness of flexible endoscopy in the management of upper gastrointestinal tract foreign bodies at a Tertiary Hospital of Western Nepal. J Chitwan Med Coll. 2020 Jan-Mar;10(31):3-7. [Full Text]

27. Pfau PR. Removal and management of esophageal foreign bodies. Tech Gastrointest Endosc. 2014;16(1):32-9. [Eull Text | DOI]

28. Faigel DO, Stotland BR, Kochman ML, Hoops T, Judge $\mathrm{T}$, Kroser J, et al. Device choice and experience level in endoscopic foreign object retrieval: an in vivo study. Gastrointest Endosc. 1997 Jun;45(6):490-2. [PubMed | Full Text | DOI]

29. Yao CC, Wu IT, Lu LS, Lin SC, Liang CM, Kuo YH, et al. Endoscopic management of foreign bodies in the upper gastrointestinal tract of adults. Biomed Res Int. 2015;2015:658602. [PubMed | Full Text | DOI]

30. Wu WT, Chiu CT, Kuo CJ, Lin CJ, Chu YY, Tsou YK, et al. Endoscopic management of suspected esophageal foreign body in adults. Dis Esophagus. 2011 Apr;24(3):131-7. [PubMed $|\underline{\text { Full Text }}| \underline{\text { DOI }}]$

This work is licensed under a Creative Commons Attribution 4.0 International License. The images or other third party material in this article are included in the article's Creative Commons license, unless indicated otherwise in the credit line; if the material is not included under the Creative Commons license, users will need to obtain permission from the license holder to reproduce the material. To view a copy of this license, visit http://creativecommons.org/licenses/by/4.0/ 